\title{
Applications of Porous Silicon Thin Films in Solar Cells and Biosensors
}

Priyanka Singh, Shailesh N. Sharma, and N.M. Ravindra

An overview of the applications of porous silicon (PS) thin films, as antireflection coatings (ARC) in silicon solar cells and transducers in biosensors, is presented. The reflectance spectra of PS films have been compared with other conventional ARCs (such as $\mathrm{SiN}_{2}, \mathrm{TiO} / \mathrm{MgF}_{2}$ and $\mathrm{ZnS}$ ), and optimal PS ARC with minimum reflectance has been obtained. The implementation of $P S$ into an industrially compatible screen-printed (SP) solar cell by both the electrochemical etching (ECE) and chemical etching (CE) methods ane reviewed. Porous silicon films, formed via $E C E$ for short anodization times, on textured $n^{+}$emitter of c-Si solar cell having SP front and back contacts, lead to improvements in the performance of solar cells and demonstrate their viability in industrial applications.

\section{INTRODUCTION}

Porous silicon (PS) is a sponge-like structure, composed of silicon skeleton permeated by a network of pores. Porous silicon can be obtained by anodization or etching of silicon in aqueous hydrofluoric (HF) solutions and was first discovered in 1956 by Uhlir at the Bell Laboratories. ${ }^{1}$ Etching of silicon substrate generates a thin layer of porous silicon on the silicon substrate with pores as large as $-200 \mathrm{~nm}$ in diameter (as shown in Figure 1A), providing a large surface area for light trapping (in solar cell applications) and molecular interaction (in sensor applications) inside the porous layer. A scanning electron micrograph of such a PS film which has been formed on crystalline silicon (c-Si) substrate is shown in Figure 1A. The right side images illustrate the magnified top and cross-sectional view of the PS layer and clearly indicate the formed pores of diameter $-200 \mathrm{~nm}$ in the PS film. ${ }^{2}$ The potential of porous silicon for various technological applications such as optoelectronic devices, ${ }^{3}$ displays, ${ }^{4}$ photodetectors, ${ }^{5}$ and biosensors $^{6}$ has been extensively investigated. Such devices can be fabricated by either varying the porosity of the PS film itself or by depositing other films on the PS film such as metals, semiconducting

How would you... ...describe the overall significance of this paper?

An overview of the applications of

D porows silicon (PS) thin films as antireflection coatings (ARC) in silicon solar cells and transducers

an biosensors is presented. The implementation of PS into an

7 industrially compatible screenprinted solar cell by both the electrochemical etching and

-7 chemical etching methods are reviewed.

D...describe this work to a materials science and engineering professional with no experience in your technical specialty?

The use of porous silicon in solar cells and biosensors is described. In particular, the study facuses on

the utility of porous silicon as antirefiection coatings in solar cells. .describe this work to a layperson?

In recent years, there has been a growing interest in renewable energy sounces. Solar energy represents a non-polluting, naturally avaitable source of energy. Silicon is abundontly available in nature in the form of silica Silicon solar cells represent the largest component that facilitates the conversion of surlight to electricity. However, silticon reflects a fraction of the incident light $(-33 \%)$ which then gets wasted. Anti-neflection coatings help to minimize reflection losses. In the manuscript, we describe the use of porows silicon as an anti-refiection coating. oxides, or polymer films depending on the applications. ${ }^{7}$ The large surface-tovolume ratio of porous silicon gives it the ability to react with biochemical species and sense them readily. Recently, PS has attracted more attention due to its sensing properties and has been utilized in chemical, biological ${ }^{2,6,2-10}$ and gas ${ }^{11-17}$ sensing applications. The advantages of PS sensors are their low cost, ability to operate at room temperature, and compatibility with traditional silicon device fabrication technology. Furthermore, interest in porous silicon in the solar cell industry has grown over the last decade. ${ }^{18-23}$

See the sidebar for a discussion of the formation and morphology of porous silicon.

\section{APPLICATION OF pOROUS SILICON AS ARC IN SILICON SOLAR GELLS}

As shown in Figure 2A, bare silicon surface reflects more than $30 \%$ of the incident sunlight. These reflection losses can be reduced by texturization (it is an important step during solar cell fabrication, which makes silicon surface textured) and by depositing a suitable ARC on the top surface of the solar cell, reflection losses are reduced. This is shown in Figure 2A. The ARC effect relies on destructive interference of waves reflected at the top and bottom of the ARC, as shown in Figure 2B. It can be seen from Figure $2 B$ that $P_{1}$ and $\mathrm{PS}_{2}$ are two ARCs formed on c-Si solar cell via ECE formation results in a very low reflectance in a certain wavelength range, which for photovoltaic applications must lie between 650 and 700 nm. ${ }^{2 s}$

For example, in Figure 2A, $\mathrm{PS}_{2}$ shows $-5 \%$ reflectance in the wavelength range of 650 and $700 \mathrm{~nm}$. For an 
optimal ARC on a silicon substrate, the required refractive index and thickness is given by:

$$
\begin{gathered}
n_{A B C}=\sqrt{n_{S i} n_{\alpha i r}} \\
d_{A B C}=\frac{\lambda_{\min }}{4 n_{A R C}}
\end{gathered}
$$

where, $n_{\mathrm{si}}$ is the refractive index of $\mathrm{c}$ $\mathrm{Si}$ which depends on wavelength $\mathbf{3 . 8 4}$ at $650 \mathrm{~nm}, 3.76$ at $700 \mathrm{~nm}$ ), and $n_{\text {dir }}$ is the refractive index of air. According to Equation 1, the refractive index (n) of an optimized ARC material on silicon should be equal to 1.96 at $650 \mathrm{~nm}$ and 1.94 at $700 \mathrm{~nm}^{28}$ Hence, from Equa-

\section{FORMATION AND MORPHOLOGY OF POROUS SILICON}

\section{Formation}

The most common method for fabricating porous silicon (PS) is the electrochemical etching (ECE) of silicon in HF based electrolyte. The electrolyte contents used for PS formation may vary substantially. However, the electrolyte is generally a mixture of aqueous $\mathrm{HF}$ and ethanol $\left(\mathrm{CH}_{3} \mathrm{CH}, \mathrm{OH}\right)$. Ethanol is used as a surfactant to facilitate extraction of hydrogen bubbles formed during etching.2024 Electrochemical anodization is usually performed in an especially designed Tefion cell, using a two-electrode arrangement as shown in Figure 1B. The back of the silicon wafer is held strongly in contact with a metallic copper plate which acts as anode. The PS formation process is performed at a constant current density. The platinum electrode acts as cathode which is positioned in the electrolyte above the silicon surface that is to be etched. The PS film fabricated using this method is generally homogenous in both porosity and thickness. ${ }^{24}$

An alternative method for processing PS is stain or chemical etching $(C E)$ which requires the dipping of silicon substrate in a solution of $\mathrm{HF}$, nitric acid $\left(\mathrm{HNO}_{3}\right)$, and water $\left(H_{2} \mathrm{O}\right)$. No external bias is used in this process. ${ }^{24}$ Nevertheless, the PS formed using this method is inhomogeneous in both porosity and thickness due to the fact that hydrogen

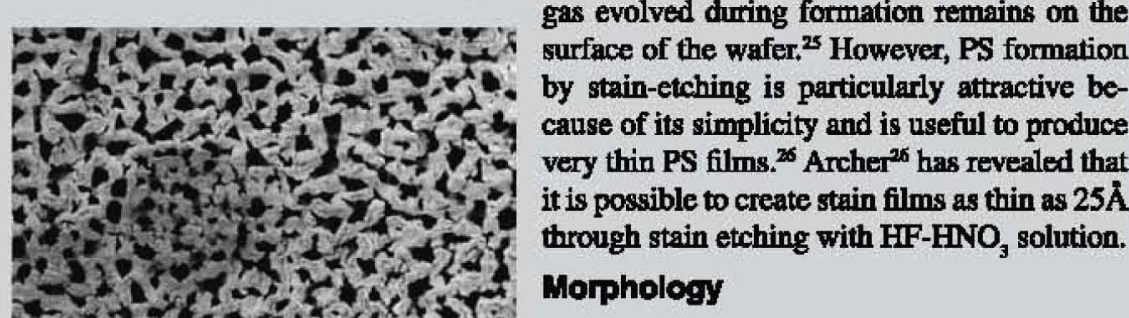

Porous silicon morphology (i.e., pore size, porosity, and pore depth) depends on the type of silicon wafer, its resistivity, method of PS formation (i.e., $\mathrm{ECE}$ or $\mathrm{CE}$ ) and on process conditions such as current density, HF concentration, HF: $\mathrm{C}_{2} \mathrm{H}_{5} \mathrm{OH}$ ratio in BCE and HF:HNO, ratio in $\mathrm{CEE}^{2427}$ Figure A shows the morphology of three PS films prepared for HF concentrations of (a) $12.5 \%$, (b) $16.7 \%$, and (c) $25 \%$, in which PS films are prepared by electrochemical etching on p type c-Si wafer. The scanning electron micrograph of the surface of PS film (a), in Figure A, reveals its highly porous nature; film (b) exhibits lower porosity. The top view of the film (c) surface reveals no

b

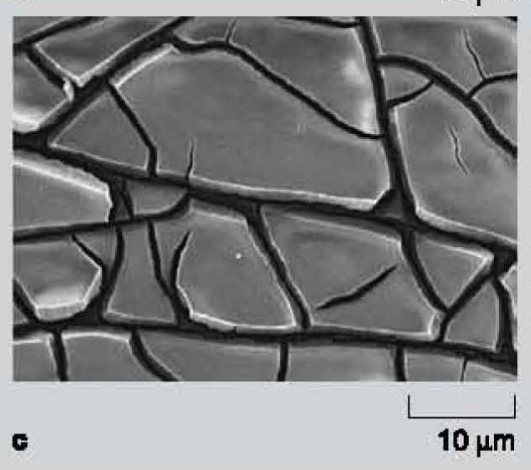

tions 1 and 2, an ARC thickness (d) of $83 \mathrm{~nm}(90 \mathrm{~nm})$ is required to produce a zero net reflectance at $650 \mathrm{~nm}(700$ nm).

Table I summarizes the available ARC materials and their refractive indices. ${ }^{29,30}$ In order to cover a broad range of the solar spectrum, double layer anti reflection coatings (DLARC) have been investigated by several authors. ${ }^{31-33}$ Higher refractive index materials (from 2.2 and 2.6) are preferred as bottom layer films and lower refractive index materials (from 1.3 to 1.6 ) are generally used as top layer films in DLAR coatings. $\mathrm{MgF}_{2} / \mathrm{ZnS}, \mathrm{MgF}_{2} / \mathrm{TO}_{2}$, and $\mathrm{SiO}_{2} /$ SiN, have been reported as DLAR coating materials. ${ }^{34}$ Canham et al. ${ }^{24}$ have established that a PS film used as an ARC should be $60 \%$ porous to exhibit an optimal $n_{A R C}$ value. The PS refractive index varies from 1.25 to $3,24,35$ therefore, the additional capability of PS films as single and double layer ARC is evident.

\section{Reflectance of Porous Silicon Films}

The comparative analysis of the reflectance spectra of PS films with other conventional ARCs will shed more light on this aspect of PS films. Figure 3 shows the reflectance of PS films along with other ARCs, such as double layer $\mathrm{TiO}_{2} / \mathrm{MgF}_{2}, \mathrm{SiN}_{\mathrm{z}}$ and $\mathrm{ZnS} .^{20,35-37}$ In Figure 3A-C, PS films are formed on $\mathrm{n}^{+}$emitter of multicrystalline silicon (me-Si), SP solar cell. In Figure 3D, PS films are formed on $\mathrm{n}^{+}$emitter of SP c-Si solar cell. In Figure 3A, PS films are formed via chemical etching ${ }^{35}$ and in Figure 3B-D, PS films are formed via electrochemical anodization using a two-electrode arrangement, ${ }^{20,36,37}$ The detailed description of these studies has been presented in the litrature. ${ }^{20,35-37}$

Figure 3A shows the reflectance characteristics of a me-Si solar cell with (a) PS and (b) double layer ( $\mathrm{TiO}_{2}$ / $\mathrm{MgF}_{2}$ ) ARC. ${ }^{20,35}$ This study has been performed by a group at FraunhoferISE (ISE) on commercial cells from ASE GmbH. ${ }^{20}$ The lower reflectance of PS ARC than that of the double layer $\left(\mathrm{TiO}_{2} / \mathrm{MgF}_{2}\right) \mathrm{ARC}$, in the wavelength range of $-600-700 \mathrm{~nm}$, clearly exhibits its better anti-reflecting properties for applications in solar cells. ${ }^{35}$

In a recent study by Kwon et al. ${ }^{36}$ the tion; on the other hand, many large cracks have been observed. PS films prepared at a curnent higher than $25 \%$ showed surface morpholog similar to sample (c), ${ }^{27}$ with different HF concentrations: (a) $12.5 \%$, (b) $16.7 \%$, and (c) $25 \%$. Anodization current is $10 \mathrm{~mA} \mathrm{~cm}^{-2}$.

FigureA.Topviewsecanningelectron micrographs 
Table I. Refractive Indlces (n) for Varlous Antirefiectlon Coating Materials Corresponding to Wavelength of 650 to $700 \mathrm{~nm}^{\mathrm{e}} \mathrm{aln}$

\begin{tabular}{|c|c|}
\hline Material & $\begin{array}{l}\text { Refractiwe Indox } \\
\text { (n) }\end{array}$ \\
\hline$\overline{\mathrm{C}}$ & 1.95 \\
\hline $\mathrm{C} 6 \mathrm{O}_{2}$ & $2.30-2.40$ \\
\hline $\mathrm{Al}_{2} \mathrm{O}_{3}^{2}$ & $1.80-1.90$ \\
\hline Glass & $1.50-1.70$ \\
\hline $\mathrm{MgF}_{2}$ & $1.30-1.40$ \\
\hline $\mathrm{MgO}^{2}$ & 1.74 \\
\hline $\mathrm{Si}_{3} \mathrm{~N}_{4}$ & 1.90 \\
\hline Sio ${ }^{4}$ & $1.80-1.90$ \\
\hline $\mathrm{SOO}_{2}$ & 1.46 \\
\hline $\mathrm{TIO}_{2}^{-}$ & 2.30 \\
\hline T8, & $2.10-2.30$ \\
\hline $\operatorname{ZnS}$ & 2.33 \\
\hline
\end{tabular}

reflectance of (a) PS ARC is found to be quite comparable to the reflectance of (c) conventional $\mathrm{SiN}_{x}$ ARC on a (b) textured mc-Si in the wavelength range of $-600-700 \mathrm{~nm}$ (Figure 3B). It can be seen that PS ARC shows a minimum reflectance of $-3.1 \%$ at $570 \mathrm{~nm}$ and $\mathrm{SiN}_{x}$ ARC shows a minimum reflectance of $-2.0 \%$ at $730 \mathrm{~nm}$. As a result, PS ARC demonstrates optical performance that is superior to vacuum-deposited $\mathrm{SiN}_{\mathbf{x}}$ ARC film. In addition, PS is formed uniformly on the entire area of the mcSi wafer. ${ }^{36}$

The reflectance of a solar cell with an optimized (a) PS ARC and (b) with a SiN ARC is shown in Figure 3C. In this work, PS has been formed on mc-Si solar cells with a very large area $(100$ $164 \mathrm{~cm}^{2}$ ). It is clearly seen that similar reflectance is obtained for PS and for the conventional $\mathrm{SiN}_{\mathrm{x}} \mathrm{ARC}^{20}$ This indicates the advantages of PS as ARC to make solar cells cost effective.

The reflectance spectra of the c-Si solar cells with ARCs (a) $\mathrm{PS}_{1}$, (b) $\mathrm{PS}_{2}$, (c) $\mathrm{ZnS}$, and (d) without ARC, in the wavelength range of $360-600 \mathrm{~nm}$ are shown in Figure 3D, ${ }^{37} \mathrm{PS}_{1}$ and $\mathrm{PS}_{2}$ are two porous silicon films deposited on $\mathrm{n}^{+}$emitter of c-Si solar cells at different charge densities $Q_{1}=0.06 \mathrm{C} / \mathrm{cm}^{2}$ and $Q_{2}=0.9 \mathrm{C} / \mathrm{cm}^{2}$, respectively. It can be seen that, in the entire investigated range of wavelengths, the reflectance of the samples with (a) $\mathrm{PS}_{1}$, (b) $\mathrm{PS}_{2}$ ARC is less, compared to (c) ZnS ARC and (d) without ARC. It is clear that, in the wavelength range of $550-600 \mathrm{~nm}$, both $\mathrm{PS}_{1}$ and $\mathrm{PS}_{2}$ show significantly less reflectance ${ }^{37}$ and, hence, PS exhibits good anti-reflecting properties in solar cell applications.

In this work, we have formed PS films via $\mathrm{ECE}$ technique in a mixture of $\mathrm{HF}$ and $\mathrm{C}_{2} \mathrm{H}_{3} \mathrm{OH}$ (1:1 by volume) using $\mathrm{Si}$ as the anode and $\mathrm{Pt}$ as the counter electrode as shown in Figure 1B. PS has been formed on $\mathrm{n}^{+}$textured emitter of c-Si SP solar cell (area $10 \mathrm{~cm}^{2}$ ) at varying current density (J-10-40 mA $\mathrm{cm}^{-2}$ ) and time (t-20 s to $60 \mathrm{~s}$ ). Figure 2A shows the reflectance spectra of two such PS films; $P_{1}$ and $P_{2}$ along with bare and textured silicon surfaces as a function of wavelength in the range $400-1,100 \mathrm{~nm}$. PS 1 corresponds to current density (J) of $10 \mathrm{mAcm}^{-2}$ and time (t) of $30 \mathrm{~s}$ whereas $\mathrm{PS}_{2}$ corresponds to $\mathrm{J}=20 \mathrm{mAcm}^{-2}$ and $\mathrm{t}=20 \mathrm{~s}$. It can be seen from Figure 2A that PS $_{2}$ ARC shows lower reflectivity values in the most useful part of the solar spectrum $\left(\lambda_{\mathrm{mln}}=650-700 \mathrm{~nm}\right)$ as compared to $\mathrm{PS}_{1}$. Therefore, it is important to note here that an optimal PS can be obtained by varying current density and time.

These results clearly indicate that PS can be implemented as ARC in industrial solar cells and can possibly replace other conventional single and double layer ARCs.

\section{Application of Porous Silicon in Industrial Solar Cells}

Industrial solar cells are generally fabricated on large area $\left(-100 \mathrm{~cm}^{2}\right) \mathrm{Cz}$ c-Si or mc-Si substrates using low-cost processing techniques to obtain a relatively good efficiency at reduced cost. Typical efficiency of commercially produced c-Si solar cells lies in the range of $-13-17 \%$. The efficiency of solar cells depends on processing techniques and influence the production cost at all production stages. Therefore, substantial effort is directed toward efficiency improvement. The industrial solar cell processing steps involve texturization, phosphorous diffusion (to make p-n junction), realization of front and back

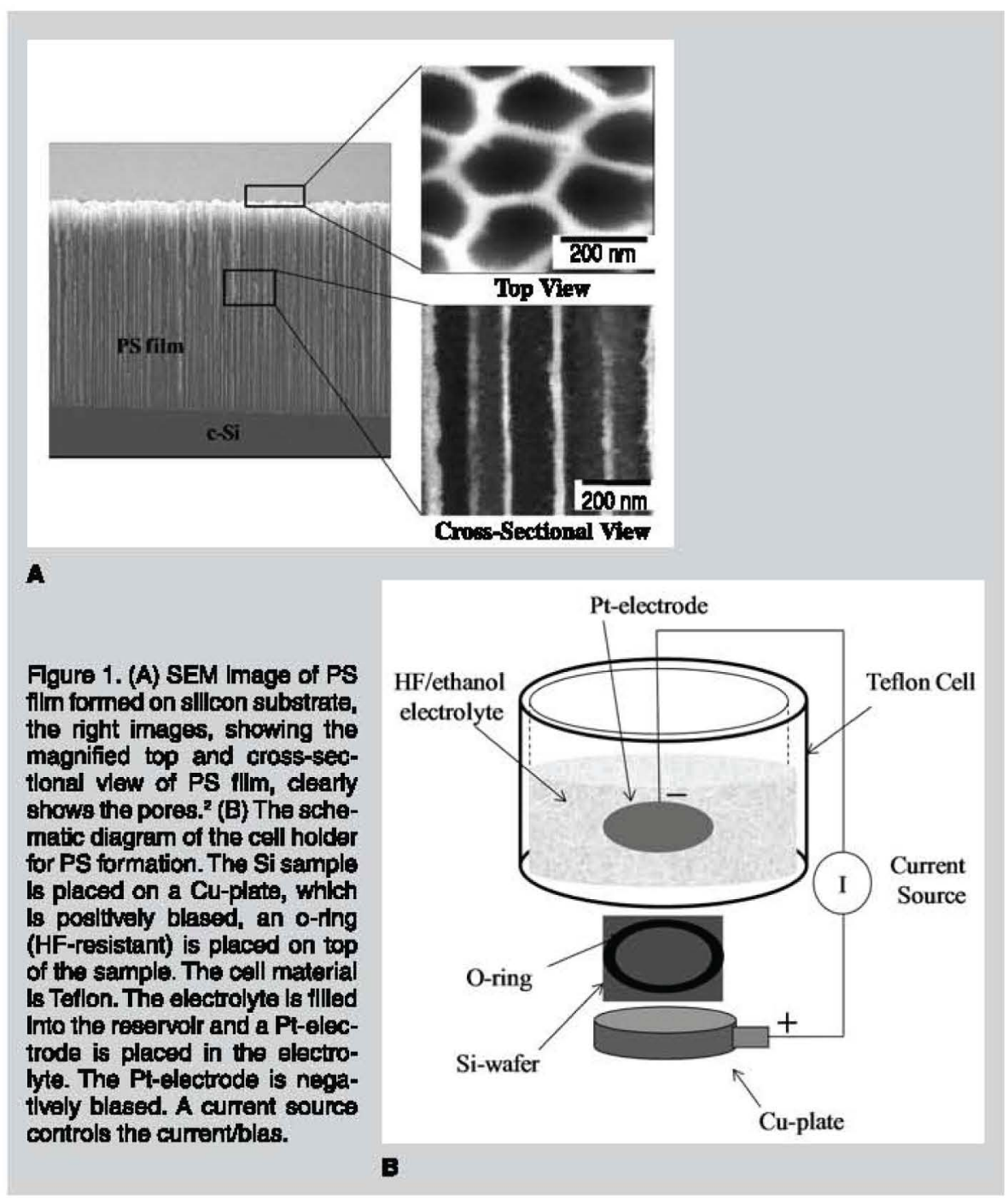




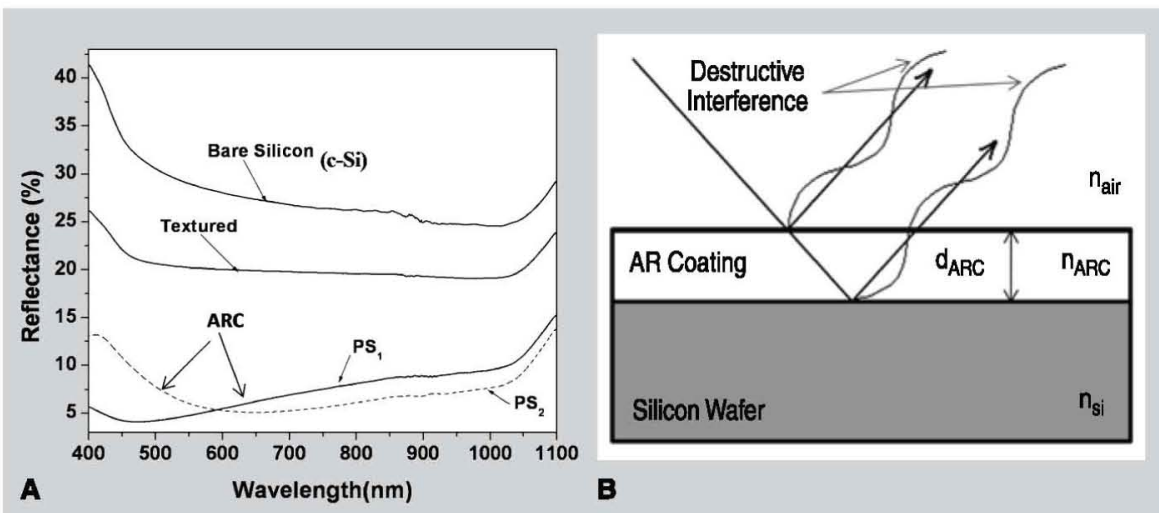

Figure 2. (A) The measured reflectance of the ARCs; PS $\left(J=10 \mathrm{~mA} \mathrm{~cm} \mathrm{~m}^{-2}, t=30 \mathrm{~s}\right)$ and $\mathrm{PS}_{2}\left(\mathrm{~J}=20 \mathrm{~mA} \mathrm{~cm}{ }^{-2}, \mathrm{t}=20 \mathrm{~s}\right)$ formed on $\mathrm{c}-\mathrm{Si}$ solar cells along with bare and textured silicon surface; $(B)$ principle of anti-reflection coating.

contacts using screen printing techniques followed by deposition of antireflection coating. The schematic representation of one such c-Si solar cell by Sun Power is shown in Figure $4,{ }^{38}$ where the expected solar cell efficiency is $\sim 29 \%$. However, various losses such as reflection, recombination and resistive losses reduce the cell efficiency to $14.7 \%$. It can be seen from Figure 4 that the total losses account for $14.3 \%$, wherein $1.8 \%$ of the reflection losses are due to front metallic grid structure and $0.4 \%$ reflection losses are after texturization and ARC deposition. The main attraction of porous silicon in the photovoltaic (PV) industry is to use it as a cost effective ARC for large-scale applications. The main advantage of PS as an ARC (as discussed in the preceding section) is well known; it reduces the reflection losses resulting from the silicon surface. Furthermore, PS has a large active area and is capable of light down-shifting in energy or photon energy down-converter (ultraviolet to visible). The use of PS films in solar cells has led to a reduction in the surface recombination velocity, enhancement of the spectral response in the short-wavelength region, and increase in the photogeneration velocity of charge carriers. ${ }^{18-24}$ Porous silicon can also serve as a wide bandgap absorber in a multiplejunction cell structure, with $\mathrm{c}-\mathrm{Si}$ as the substrate. ${ }^{24}$ Attempts have been reported to use two PS films with two different bandgaps in a three-bandgap solar cell on a silicon wafer. ${ }^{39}$

Porous silicon ARC formed via ECE or CE on finished solar cells has a serious problem of fill factor degradation due to the increase in series resistance $\left(R_{s}\right)$. Screen printed metalized contacts make direct contact with HF solution during PS formation and therefore degrade the quality of the SP contacts. In order to avoid this degradation problem, the following two approaches can be adopted. In the first approach, ECE can be performed for a short time and this seems to be more convenient for largescale implementation of PS in finished SP solar cells. ${ }^{20}$ In the second approach PS formation can be done on the heavily doped $\mathrm{n}^{+}$emitter surface prior to the contact metallization step. ${ }^{20}$ However, it is very difficult to obtain a stable ohmic contact on PS layer because of the large surface state density. ${ }^{40}$ Therefore, ECE on finished solar cells, for short times seems to be a better option to obtain a homogenous PS ARC. Moreover, in ECE by varying the current density and time, it is possible to obtain PS films with varying refractive indices and thicknesses. ${ }^{35}$ Both the methods have been applied to SP silicon solar cells. ${ }^{20,35,36,41,42}$ The results of PS ARC implementation using chemical and electrochemical methods in industrial mc-Si solar cell processing are presented in these studies. ${ }^{20,35,36,41-43}$ We have formed PS ARC for short anodizaion times via ECE on finished solar cells. Solar cells have been fabricated on c-Si (p-type) wafer using industrial processing steps as described above and have silver fingers on the front side and Ag-Al contact on back side.

A research group at the Università Roma Tre (RM3) ${ }^{43}$ and a group from Fraunhofer-ISE (ISE) ${ }^{35}$ implemented stain-etched PS ARC on screen printed mc-Si solar cell that is currently used in the PV industry. RM3 used the solar cells from Eurosolare S.p.A. ${ }^{43}$ whereas ISE used commercial cells from ASE GmbH..$^{35}$ The electrochemical method has been applied by Interuni- versity Microelectronics Center, Belgium (IMEC) and Centre National de la Recherche Scientifique-Laboratoire de Physique des Solides de Bellevue (CNRS-LPSB). ${ }^{20}$ The efficiency potential of a PS ARC has been investigated by the Interuniversity Microelectronics Center, Belgium on high-quality FZ Si substrates $\left(2 \times 2 \mathrm{~cm}^{2}\right) .{ }^{20}$ Centre National de la Recherche Scientifique-Laboratoire de Physique des Solides de Bellevue focuses on the formation of PS ARC for commercial mc-Si solar cells $\left(5 \times 5 \mathrm{~cm}^{2}\right)$ and the PS film is formed at a constant current density of $50 \mathrm{mAcm}^{-2}$ for $3.5 \mathrm{~s}$. The details of solar cell processing and PS formation are described in the following publications. ${ }^{20,43}$ From our recent studies, it is found that the properties of PS formed using screenprinted silver and aluminum as the back contacts are superior as compared to the corresponding films with evaporated back contacts. ${ }^{44}{ }^{46}$ The PS films formed with screen-printed silver and aluminum-back contacts show better crystalline perfection, higher stability, higher Photoluminescence (PL) efficiency and negligible PL decay compared to that formed with evaporated silver and aluminum as the back contact for the same current density and time of anodization. The results conclusively demonstrate the viability of screen-printing contact technology for the possible application of PS films in Si-solar cells. ${ }^{44-46}$

Table II summarizes the measured photovoltaic performance parameters; current density $\left(\mathrm{J}_{\mathrm{sc}}\right)$, open circuit voltage $\left(V_{o c}\right)$, fill factor (FF) and efficiency $(\eta)$ under global AM1.5 illumination for chemical and electrochemical etching on mc-Si solar cells before and after PS formation. In chemical etching, the efficiency of ISE solar cells increases after PS formation; however, the fill factor degraded which may be attributed to the increase in $R_{s}$, mainly due to the interaction of HF acid with glass-containing silver paste in SP contacts. ${ }^{35}$ In the RM3 cells, the metallization is protected by a polymeric film which explains the smaller degradation of $R_{s}$, and hence the achieved higher FF and efficiency. ${ }^{43}$ In electrochemical etching, it can be seen from Table II that efficiency of $14.6 \%$ and $13.2 \%$ has been obtained on the solar cells of IMEC and CNRS-LPSB, respectively. After PS formation, fill 
factor does not change in IMEC solar cells, whereas fill factor increases for CNRS-LPSB. The characteristics of the cell $\left(5 \times 5 \mathrm{~cm}^{2}\right.$ Polix mc-Si) with the PS film $(\eta-13.2 \%)$ are similar to commercial cells. ${ }^{20}$ Table II also lists the results obtained for optimal PS ARC (PS 2 -Figure $2 \mathrm{~A}$ ), implemented on a screen printed c-Si solar cell. It has led to $20.8 \%$ relative improvement in $\mathrm{J}_{\mathrm{sc}}$, a significant gain of $\sim 15 \mathrm{mV}$ in $\mathrm{V}_{\alpha}$ and a relative increment of about $~ .3 \%$ in FF. This yields a $~ 26 \%$ increase in efficiency. In a study by Kwon et al., ${ }^{36}$ the optimization of a PS selective emitter in a screen printed mc-Si $\left(2 \times 2 \mathrm{~cm}^{2}\right)$ solar cell results in a $13.2 \%$ efficiency with electroplating. ${ }^{36}$

Thus, PS has immense potential as ARC in commercial solar cell application. Simplicity and low cost of the ECE technique as well as its adaptation to silicon solar cell manufacturing provides a very promising technology in an industrial process.

\section{Characterization of Porous Silicon Films}

The surface morphology of PS films has been studied by scanning electron microscope (SEM) and atomic force microscope (AFM). Figure 5A and $B$

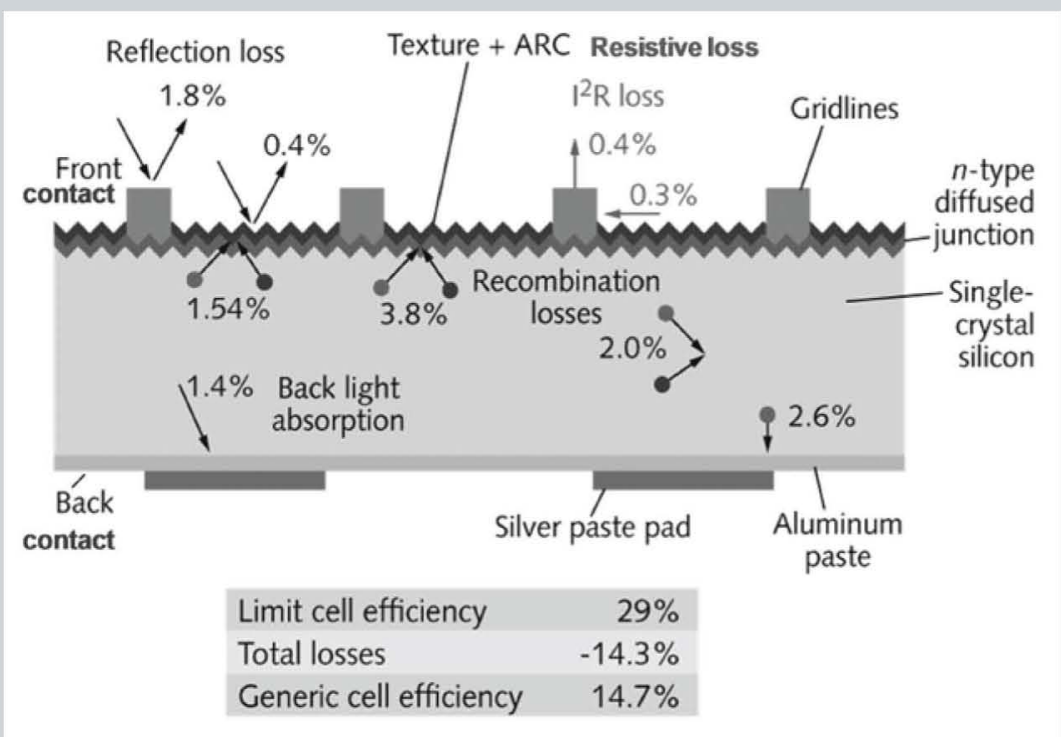

Figure 4. Multiple losses (such as reflection, recombination and resistive) in a single crystal silicon solar cell. ${ }^{38}$ (Courtesy of SunPower) shows surface morphology, as seen by SEM and AFM for film $\mathrm{PS}_{2}$, which has been formed on $\mathrm{n}^{+}$emitter of textured c$\mathrm{Si}$ solar cell. As can be seen from Figure $5 \mathrm{~A}$, the textured surface shows uniform large pyramids of sizes varying from 1 to $10 \mu \mathrm{m}$ approximately. The SEM image indicates that the front screen printed silver finger has not been damaged after PS formation. Figure 5B shows
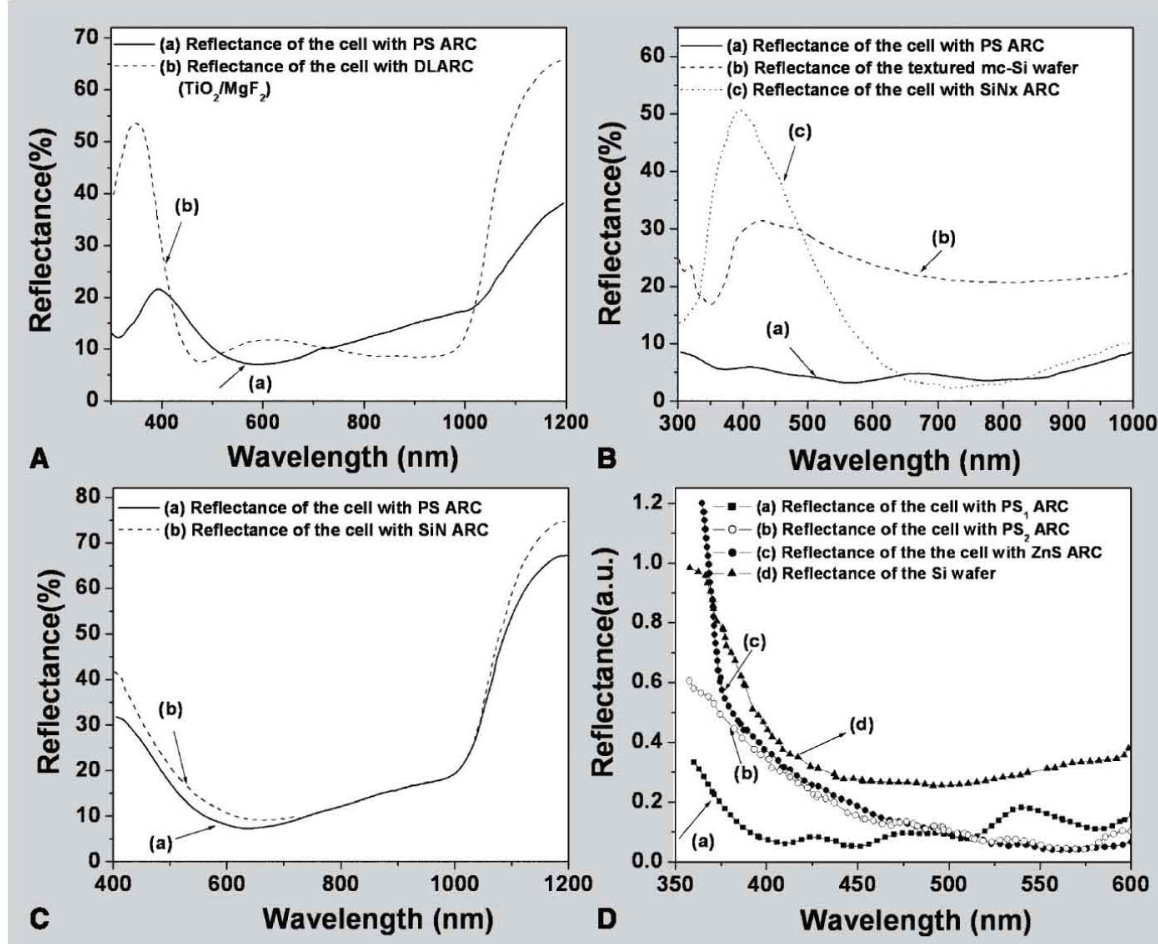

Figure 3. (A) Reflectance characteristics of cells with (a) PS ARC and (b) double film (TiO, $\mathrm{MgF}_{2}$ ) ARC; ${ }^{20,35}$ (B) reflectance characteristics of (a) PS ARC (b) alkaline-textured mc-Si wafer, and (c) single-film $\mathrm{SiN}_{x} \mathrm{ARC} ;{ }^{36}$ (C) reflectance characteristics of mono-Si cells with (a) PS ARC and (b) with conventional SiN ARC;20 (D) reflectance spectra of samples with ARCs (a) $\mathrm{PS}_{1}$, (b) $\mathrm{PS}_{2}$, (c) ZnS and (d) without ARC. ${ }^{37}$ three-dimensional (3-D) picture of PS layer, which consists of irregular upright surface features with typical size distribution of $\sim 150-500 \mathrm{~nm}$ or even smaller, where the maximum pore size is $\sim 500$ $\mathrm{nm}$ long and $\sim 50 \mathrm{~nm}$ wide whereas the minimum pore size is $\sim 150 \mathrm{~nm}$ long and $\sim 30 \mathrm{~nm}$ wide. Such types of structures are generally observed in PS films. ${ }^{24}$

Fourier transform infrared (FTIR) analysis is widely used to characterize the bonding properties in PS films. Here, we present FTIR and photoluminescence (PL) spectra on PS films of various thicknesses, formed on $p$ type c-Si wafer via ECE. In this work, PS films of various thicknesses are formed at optimized current density $(J)$ of 20 $\mathrm{mA} \mathrm{cm} \mathrm{cm}^{-2}$ with time $(\mathrm{t})$ variation from 1 to 20 minutes, respectively. ${ }^{45}$ As current density increases, the thickness of PS film increases. ${ }^{44}$ The PS films of various thicknesses, (a)-(e) in Figure $6 \mathrm{~A}$ and $\mathrm{B}$, are formed at a constant $\mathrm{J}$ of $20 \mathrm{~mA} \mathrm{~cm}{ }^{-2}$ and at time $\mathrm{t}=1 \mathrm{~min}, 2$ min., $5 \mathrm{~min}$., $20 \mathrm{~min}$., and $30 \mathrm{~min}$., respectively. ${ }^{45}$ The thickness of PS films, (a) and (b), are $\sim 150 \mathrm{~nm}$ and $\sim 200 \mathrm{~nm}$, respectively, as measured by an ellipsometer; for films (c)-(e), the thickness varies from 5 to $20 \mu \mathrm{m}$ as estimated from gravimetric measurements. ${ }^{18}$ Corresponding FTIR and PL spectra are recorded for these PS films (Figure $6 \mathrm{~A}$ and $\mathrm{B}$ ).

Figure 6A shows the FTIR spectra of PS films of various thicknesses (a)-(e). During PS formation, a large number 
of Si-hydride bonds as well as Si-hydroxide bonds are formed and possibly passivate the Si/PS interface. ${ }^{47}$ It can be seen in Figure 6A that PS films exhibit mainly $\mathrm{Si}-\mathrm{H}$ related modes at -2101 $\mathrm{cm}^{-1}$ due to $\mathrm{Si}-\mathrm{H}$ stretching mode, -910 $\mathrm{cm}^{-1}$ due to $\mathrm{Si}_{-} \mathrm{H}_{2}$ scissors or $\mathrm{Si}-\mathrm{H}_{3}$ symmetric or antisymmetric deformation, doublet $-666 \mathrm{~cm}^{-1}$ and $627 \mathrm{~cm}^{-1}$ due to $\mathrm{Si}-\mathrm{H}_{2}$ and $\mathrm{Si}-\mathrm{H}$ wagging while $\mathrm{Si}-\mathrm{O}$ related modes are marked by very weak signatures at $-1,035 \mathrm{~cm}^{-1}$ due to a bulk interstitial Si-O-Si asymmetric stretching model. ${ }^{18,20,45}$

As the thickness of PS films increase (i.e., FTIR spectra from (a)-(e)), a clear increase in both line-width and intensity of these modes can be seen. This indicates the relatively higher hydrogen content in the PS films as thickness increases. However, for very thin PS films, (a), and (b), the FTIR spectra shows only weak signatures of these bands. The distinct presence of Si-H stretching mode at $-2,101 \mathrm{~cm}^{-1}$ represents the quality of passivation for PS films (d) and (e). Small peak at $\sim 2,308 \mathrm{~cm}^{-1}$ can be related to $\mathrm{O}$ back-bonded to $\mathrm{Si}$ in Si-H stretching mode. ${ }^{48}$ Similar FTIR results on PS films are also discussed in the Reference 20.

Figure 6B shows the corresponding room temperature PL spectra of these PS films (a)-(e). The thin porous silicon film (a) does not exhibit any PL properties which may be attributed to the weak signals of Si-H bands in the FTIR spectra. However, a weak PL can be seen

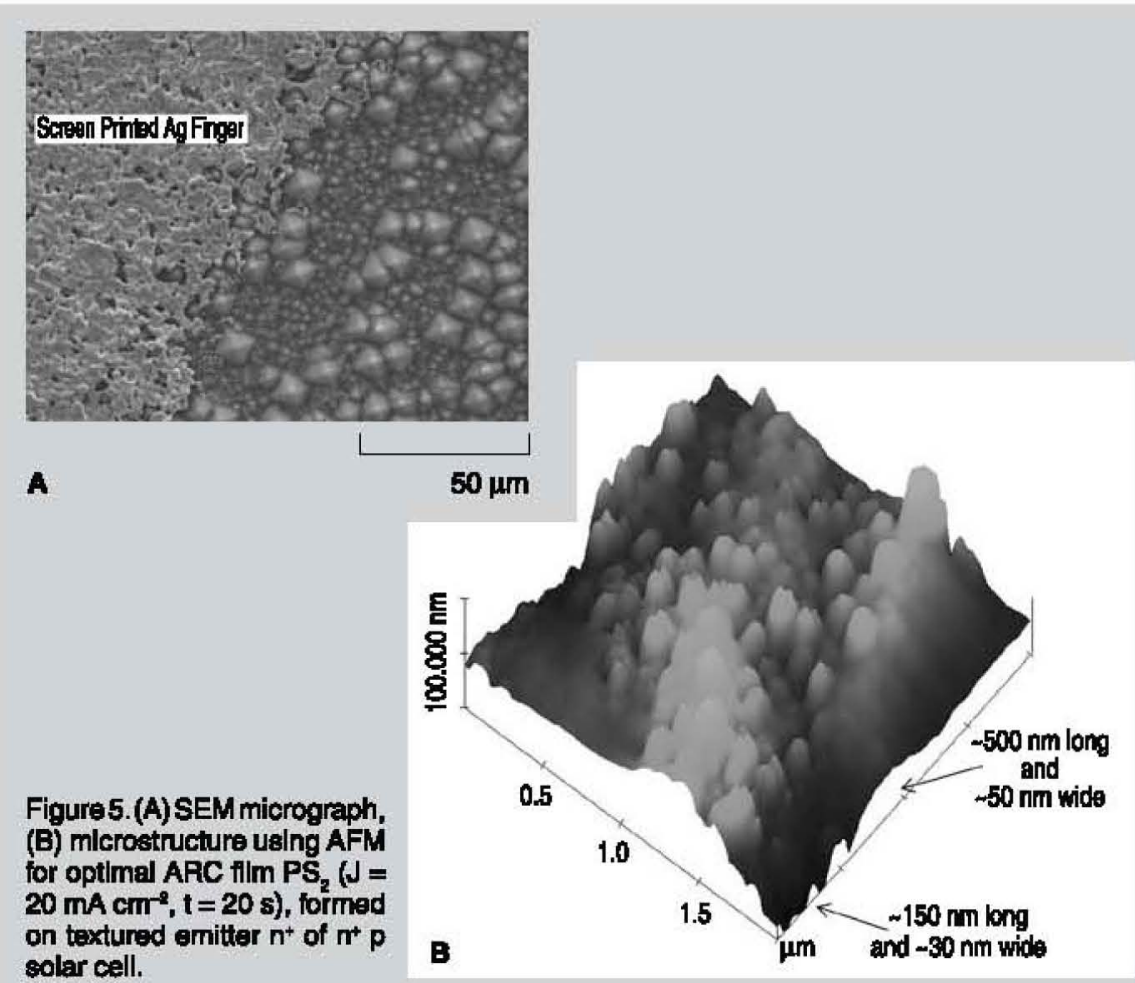

for PS films (b) and (c) which may be attributed to the increase in intensity of Si-H and related bands in the FTIR spectra. The absence of $P L$ properties in PS film (a), and weak PL for films (b) and (c) are apparently due to the silicon skeletons not being narrow enough for quantum confinement. The PL intensity increases as PS film thickness increases (from (a)-(e)) as shown in Figure 6B and a sharp peak at $-688 \mathrm{~nm}$ has been obtained for the PS films (d) and (e) corresponding to 10 and 30 minutes of PS formation. The increase in the corre-
Table II. Measured Photowoltaic Parameters; Current Density $(U$ ), Open Circuit Voltage $\boldsymbol{N}_{\infty}$, Fill Factor (FF), and Efficiency $(\eta)$ undar Clobal AM1. 5 Illumination on Soler Cells using Chemical and Electrochemical PS Formation"

\begin{tabular}{|c|c|c|c|c|c|c|c|}
\hline PS Procens & Colls From & ARC & Area & $\underset{\left(m^{2}\right)}{d}$ & $\underset{(m A c m-\infty}{V_{w}}$ & $\begin{array}{l}F F \\
(\mathrm{mV})\end{array}$ & $\pi$ \\
\hline \multirow[t]{4}{*}{ Chemleal } & ASE (ISE) & No ARC & 100 & 22.3 & 575 & 0.774 & 9.9 \\
\hline & $\begin{array}{c}\text { ASE(ISE) } \\
\text { (Eurosolare) }\end{array}$ & PSARC & 100 & 28.9 & 574 & 0.740 & 12.3 \\
\hline & RMB & No ARC & 164 & 22.4 & 588 & 0.685 & 8.0 \\
\hline & $\begin{array}{c}\text { RMB } \\
\text { (ASE GmbH) }\end{array}$ & PS ARC & 164 & 27.2 & 582 & 0.753 & 12.1 \\
\hline \multirow[t]{6}{*}{ Elextrochemical } & IMEC & $\begin{array}{c}\text { PS ARC } \\
\text { (nen-textured) }\end{array}$ & 4 & 30.4 & 608 & 0.78 & 14.3 \\
\hline & IMEC & PS (textured) & 4 & 31.3 & 601 & 0.78 & 14.6 \\
\hline & CNRS-LPSB & No ARC & $\mathbf{2 5}$ & 31.6 & 595 & 0.73 & 13.6 \\
\hline & CNRS-LPSB & PS ARC & 25 & 30.4 & 583 & 0.74 & 132 \\
\hline & Present work & No ARC & 10 & 19.7 & 545 & 0.67 & 7.15 \\
\hline & Present work & PS ARC & 10 & 23.8 & 560 & 0.68 & 9.01 \\
\hline
\end{tabular}

sponding normalized PL peak intensity is correlated with the increase in the $\mathrm{Si}$ $\mathrm{H}$ and $\mathrm{Si}-\mathrm{H}_{2}$ bonds observed in the FTIR spectra. Therefore, it is worthwhile to note here that SEM, AFM, PL and FTIR studies are important characterization techniques to investigate the structural and passivating properties of PS films.

\section{APPLIGATIONS OF POROUS SILICON IN BIOSENSORS}

Biosensors have emerged as highly promising for rapid diagnosis of bacteria in foods. The general function of a biosensor is to convert a biological recognition event into an electrical or optical signal. ${ }^{49.50}$ Signal transduction has been accomplished with electrochemical, ${ }^{51}$ field-effect transistor, ${ }^{52}$ optical absorption, fluorescence and interfercmetric devices..$^{53}$ As discussed previously, ${ }^{2,6-17}$ a number of theoretical and experimental works, concerning the noteworthy properties of nanostructured porous silicon in chemical and biological sensing, have been reported, showing that, due to its morphological and physical properties, PS is a very versatile sensing platform., 2,6,-17

In our recent studies, we observed that PS films formed on textured substrates show higher PL intensity and higher lifetime values as compared to those formed on polished substrates for the same current density. ${ }^{54}$ Porous sili- 
con layers and their interfaces have been characterized by recording diffraction curves and measuring lattice mismatch/ strain and the radius of curvature due to induced biaxial stress caused by the lattice expansion of PS film due to pores. ${ }^{55}$ The higher range of strain values exhibited by PS films on textured specimens corresponding to a wide range of band gaps compared to that formed on polished specimens indicates that stable and higher porosity PS films can be formed on textured substrates at higher current densities. The larger surface area available for PS films formed on textured substrates enables the even distribution of strain, thus, leading to enhanced stability as compared to the corresponding films formed on polished specimens. ${ }^{55}$ This factor is responsible for PS films formed on textured substrates to withstand higher strain without any elastic relaxation at high current densities and can be used for gas-sensing measurements. ${ }^{56}$ In the case of PS films on polished specimens, the relaxation of the induced strain starts at relatively lower current densities as compared with PS films on textured substrates and thus is not suitable for gas-sensing applications.

The surface of porous silicon needs to be stabilized for biosensing applications and is achieved by means of oxidation, silanization, or hydrosilylation. ${ }^{57,58}$ Even without resorting to the above techniques, PS surface can be stabilized using an appropriate post-anodization treatment. At an optimum current density, passivation of defects by a novel nascent-H treatment resulted in the significant enhancement in the PL efficiency. ${ }^{59}$ The degraded PL intensity in the treated samples upon prolonged oxidation for several months was higher as compared to that for the as anodized samples. Infrared vibrational studies indicated that the enhancement in PL was due to the $\mathrm{H}$-passivation of defects in the Si-pore interface as also elucidated from capacitance-voltage studies. ${ }^{59}$ Furthermore, it has been found that HF-treated PS surfaces are relatively stable against oxidation as compared to untreated PS films. ${ }^{60}$ Upon oxidation of the HF treated PS films, the PL intensity initially increases as a result of reduction in crystallite size to exhibit quantum size effects and then decreases owing to loss of luminescing structures due to over-oxidation of the silicon columns. It can be inferred that the surface passivation either by hydrogen or oxygen is one of the requisite conditions for obtaining strong PL efficiency in PS. ${ }^{1}$ It seems that more than one emission mechanisms are responsible to explain the luminescence properties of PS. ${ }^{60}$

Furthermore, PS biosensor technology has shown great capability in detecting biological molecules with high selectivity, using specific linker agents and probe molecules. ${ }^{61}$ For the biomedical applications of PS, biomolecules have to be first immobilized on its surface through functional groups deposited on it. The common approach is to create a covalent bond between the PS surface and the biomolecules which specifically recognize the target analytes. ${ }^{61}$ The reliability of a biosensor strongly depends on the functionalization process as well as its rapidity, simplicity, homogeneity, and repeatability. ${ }^{62}$ It is well known that, after anodization, the fresh silicon surface is predominately hydride-terminated which is quite reactive and sensitive to oxidation. ${ }^{62}$ Thus, to increase the surface stability of PS, there is a need to functionalize the surface of PS by a suitable precursor. In one of our recent works, nanostructured PS surface was biofunctionalized by thermally depositing thin biocompatible films with a large density of amine groups, using 3aminopropyltriethoxysilane (APTS) on to its surface. ${ }^{63}$ The aim of the study was to demonstrate the covalent bonding between organic molecules (immunoglobulin) and modified inorganic surface (nanostructure PS) which can be used for the detection of protein signals. In this study, PS films prepared at an optimized $\mathrm{J} \sim 50 \mathrm{~mA} \mathrm{~cm}^{-2}$, having high PL intensity, stable surface bond configurations, mechanically strong structure and hydrogen-passivated surfaces were used for APTS treatment. ${ }^{63}$ The presence of reactive amino groups on the PS surface along with glutaraldehyde as a linker aids in the covalent binding of the antibody (Human IgG) onto the PS surface. ${ }^{63}$ Different antigen concentrations can be detected with a good reproducibility with this technique which opens a possibility of using this biofunctionalized material for future biosensors.

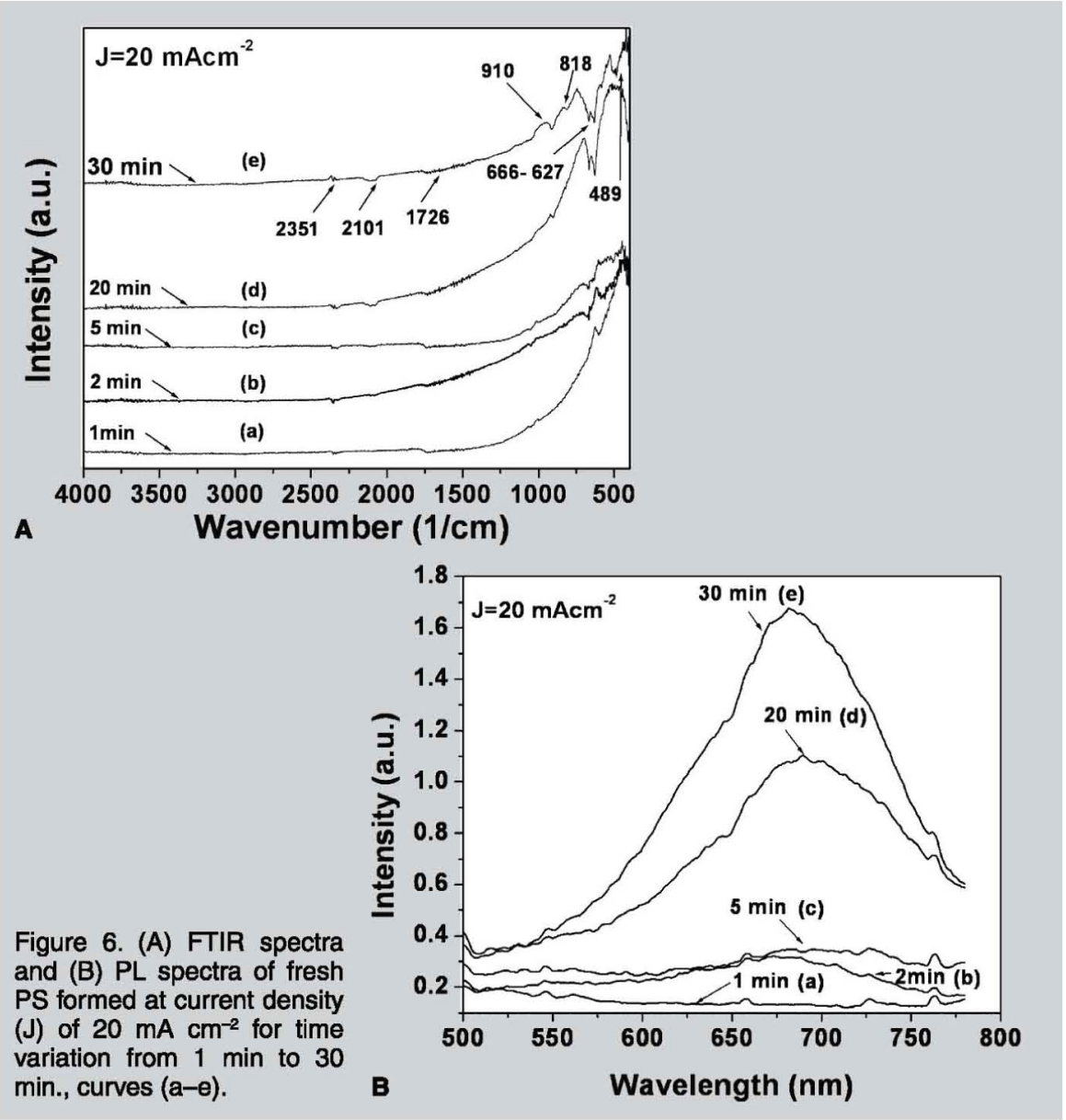


In recent developments, the process of filling the PS pores with metallic, dielectric or semiconducting oxide, enzyme, or molecular receptor films, has resulted in PS sensors that are capable of detecting penicillin, alkali metal ions, humidity, and hydrocarbons. ${ }^{64}$ In a paper by Jane et al., ${ }^{65}$ numerous PS biosensors are discussed. One category of biosensor belongs to interference effects in PS single and double layers; the second category discusses the photoluminescence-based transduction; thind category is based on PS microcavities and fourth category discusses the electrochemical transduction with porous silicon. The PS biosensors of different categories are companed on the basis of their performance, such as: concentration range, sensitivity for analyte and their detection limit. ${ }^{55}$

Silicon Kinetics has introduced nano PS biosensor and chips to monitor biomolecular interactions, ${ }^{66}$ where a nanoporous region has been formed on a c-Si wafer via electrochemical etching. Figure 7A shows the principle of nanoporous biosensor, which is based on the changes in refractive index in the PS layer, when light reflected from the top of the porous region interferes with light reflected from the bottom of the porous region and creates optical interference patterns. The optical path difference signal (OPD signal) is derived from the interferogram as in Figure $7 \mathrm{~B}$ and rises proportionately with the amount of bound biomolecules. As can be seen in Figure $7 \mathbf{B}$, the first step is to immobilize the first biomolecule of interest i.e., the target on sensor surface (with the desired surface chemistry) and, then, the solution with the second biomolecule of interest i.e., the analyte is introduced; any net binding of the analyte to the target changes the effective index of refraction in the porous region as biomolocules displace buffer solutions with lower indices of refraction. ${ }^{\text {th }}$

The simplest example of optical interferometric PS biosensor is shown in Figure $\mathbf{8 A}^{6}$ which monitors changes in the refractive index that occur in PS single- or double-layer films, wherein PS films are made via electrochemical etching of $p$ type c-Si wafer. In this sensor,

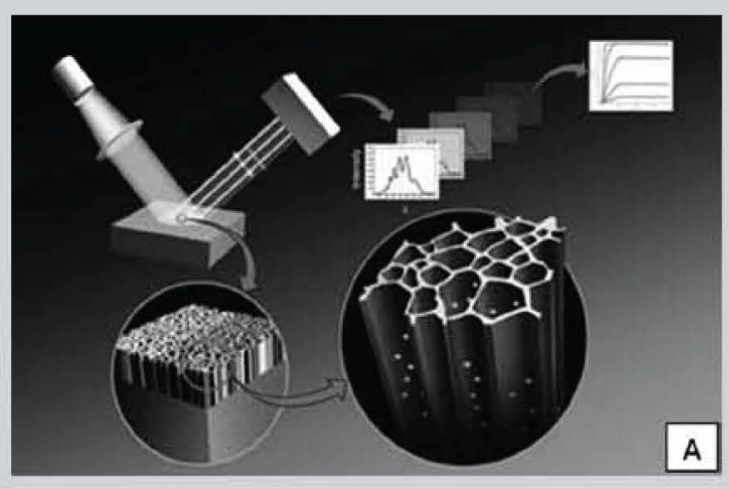

Figure 7. (A) Nanoporous blosensor princlple. (B) Schematie representation of interferogram of a typical nanoporous silicon biosensor experiment. (Source: Sillcon Knetics)

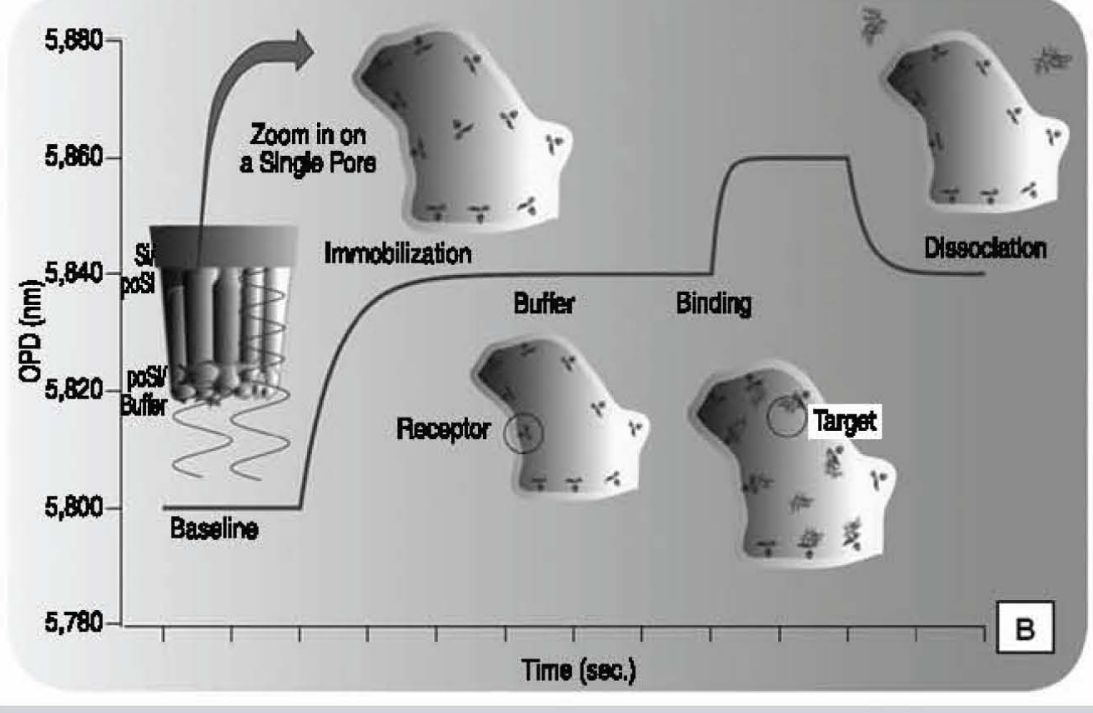

binding of molecules induces changes in the refractive index of the porous silicon films. ${ }^{6}$ The biosensor has been demonstrated for small organic molecules (biotin and digoxigenin), 16-mucleotide DNA oligomers, and proteins (streptavidin and antibodies) at pico- and femtomolar analyte concentrations. The sensor is also highly effective for detecting single and multi molecular assemblies. ${ }^{6}$

Another example is a porous silicon biosensor chip, fabricated by Mathew et al.,10 which detects Escherichia coli (E. coli) bacterium and is based on the light emitting properties of porous silicon. In this work, PS films are made via electrochemical etching of $p$ type $c-S i$ wafer and the biosensor adapts singletube chemiluminescence-based assay for detection of $E$. coli. ${ }^{10}$ The reaction of $\beta$-galactosidase enzyme from $E$. coli with the dioxetane substrate generates light at $530 \mathrm{~nm}$. Figure $8 B$ shows the light emission of a control porous silicon biosensor chip (blank with no E. coli culture) as well as that of porous- and planar-silicon biosensor chips tested with an overnight $\mathrm{E}$. coli pure culture. As shown in Figure 8B, the porous silicon biosensor chip has higher light emissions compared to the planar silicon biosensor chip due to the higher surface area of the porous chip. ${ }^{10}$ Sensitivity of the porous silicon biosensor is determined to be $10^{1}-10^{2}$ colony forming units (CFU) of E. coli.

A potentiometric biosensor for the detection of tryglycerides for metabolomics has been developed by Setzu et al. ${ }^{\text {"7 }}$ In this study, PS layers are formed on $\mathrm{n}^{+}$ type c-Si wafer by electrochemical etching. This biosensor immobilizes lipase enzyme in the PS layer and it induces hydrolysis of a triglyceride, which in turn results in a decrease in the $\mathrm{pH}$ and hence shifts the open circuit potential. This approach of immobilization of the enzyme within PS layer considerably increases the working life of the sensor as compared to other lipase-based triglyceride-detection methods.

A label-free optical biosensor for the detection of rabbitIgG(rabbit polyclonal antibody) in whole blood using a PS microcavity has been reported by Bonanno et al. ${ }^{\text {6s }}$ Porous silicon microcavities are formed via ECE into highly doped ntype silicon. Shift in wavelength enables the sensor to detect antibodies in either 
undiluted serum or whole blood ${ }^{68} \mathrm{Im}$ mobilization of antibody on PS surface is done by using biotin-streptavidin. The biosensor has exhibited linear detection range of $2-10 \mathrm{mg} / \mathrm{mL}$.

Another example of PS microcavity sensor has been reported by Ouyang et al., ${ }^{69}$ in which macroporous silicon microcavities were electrochemically synthesized from n-type c-Si wafers. This sensor is operated by analyzing the induced red-shift in the absorbance peak which is caused by the binding of an analyte to an immobilized probe molecule. The device detects an extracellular domain of intimin (intimin-ECB), a protein associated with the pathogenicity of enteropathogenic Escherichia coli. Immobilizition has been carried out by attaching probe molecules: Tir-IBD, the translocated intimin receptor-intimin binding domain, covalently to the PS surface. Intimin-ECB can be detected in a concentration of $4 \mu \mathrm{M}$ after optimizing the concentration of probe molecules.

Rossi et al. ${ }^{70}$ have developed a new method for improving the sensitivity for detection of the bacteriophage virus MS2 using thin films of nanoporous silicon. The PS films are prepared using ECE technique on polished $\mathrm{p}^{+}-\mathrm{c}-\mathrm{Si}$ wafer. They have shown that a $100 \mathrm{~nm}$ thick PS layer with a covalently immobilized antibody has a sensitivity and dynamic range similar to that of the Luminex liquid array-based assay while outperforming protein micro-array methods. ${ }^{70}$

A porous silicon optical biosensor has been developed for monitoring protein-protein binding, specifically protein A with IgG. ${ }^{71}$ Thin film of $(5 \mu \mathrm{m})$ PS has been used for immobilization and transducing matrix and the sensor operates by measurement of the Fabry-Perot fringes in the white light reflection spectrum from the PS layer. Analyte binding causes change in effective optical thickness of functionalized porous silicon Fabry-Perot film and thus transduction is achieved. Sensor demonstrates its stability, reversibility and insensitivity to nonspecific interactions.

Recently, a Fourier transformed reflectometric interference spectroscopy (FTRIFS) PS biosensor has been reported by Shang et al. ${ }^{72}$ In this setup, double layers of porous silicon films have been prepared by ECE on p-type c-Si wafers and used as a sensing element for the

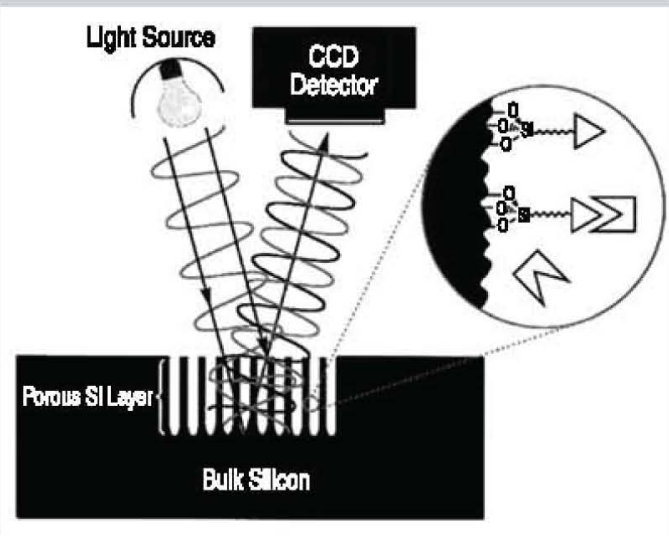

Figure 8. (A) Schematic of PSbesed optical Interferometrlc blosensor. Reflection of white light at the top and bottom of the PS film results in an interference pattern. Interactlons of molecular specles on PS surface induce a change in refractive index of nanocrystalline semiconductor, giving rise to wavelength shifts in fringe pattern that can be easlly detected by charge-coupled device (CCD) camera." (B) Comparison of light emlssion of E. coll pure culture in porous sillcon and planer sillcon biosensors against porous silicon control. ${ }^{10}$

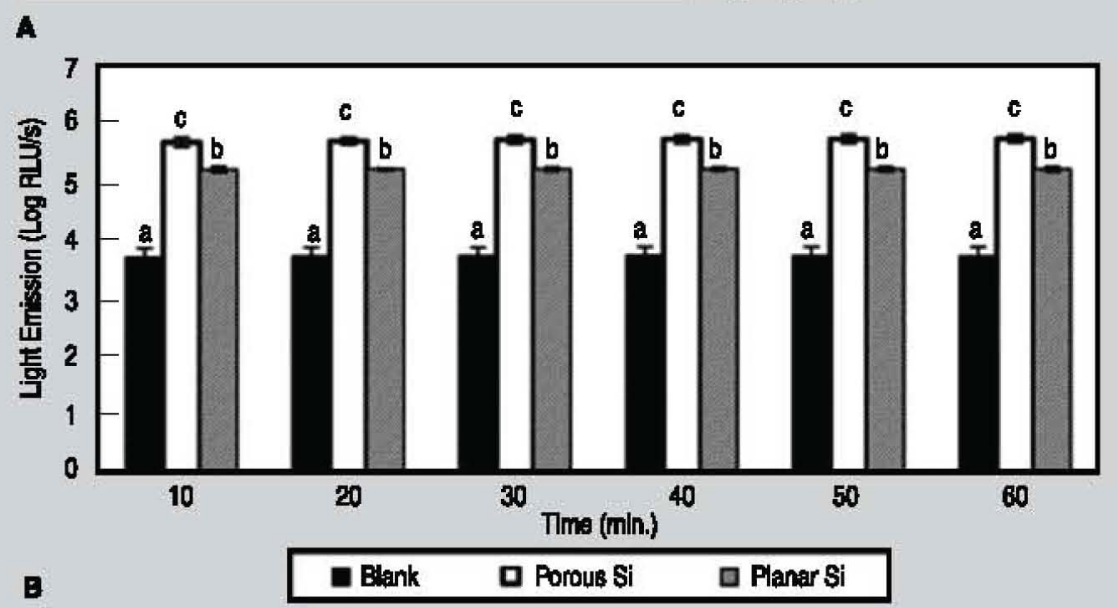

detection of target molecule by FTRIFS, where trypsin and its inhibitor are used as the model probe-target system. The FTRIFS biosensor has been combined with a UV detector for screening the target molecule from complex component mixtures separated by a LC (liquid chromatography) column, as shown in Figure 9. The outer PS layer, attached with trypsin by amino-silane and glutaraldehyde, can specifically bind with the trypsin inhibitor and acts as a sample channel, while the bottom layer serves as a reference signal channel. The binding event between trypsin and trypsin inhibitor is simultaneously detected by the FTRIFS biosensor in real-time by monitoring the change in optical thickness of the porous silicon layer. Optical signals have a linear relationship with the concentration of trypsin inhibitor in the range of $10-200 \mathrm{ng} \mathrm{mL}^{-1.72}$

\section{conclusions}

Porous silicon has a large potential for applications in photovoltaics. Reflectance of PS film is quite comparable to the reflectance of conventional ARCs (such as $\mathrm{SiN}_{\mathbf{x}}$, double layer $\mathrm{TiO}_{2} / \mathrm{MgF}_{2}$ and $\mathrm{ZnS}$ ). The PS film can be easily implemented as ARC into an industrially screen-printed solar cell by both the electrochemical and chemical etching. PS films, formed via ECE for short anodization times are applied on textured $\mathrm{n}^{+}$emitter of $\mathrm{c-Si}$ having SP front and back contacts. Implementation of optimal PS ARC has led to $-20.8 \%$ relative improvement in $\mathrm{J}_{\mathrm{se}}$, a significant gain of $-15 \mathrm{mV}$ in $\mathrm{V}_{\mathrm{oc}}$ and a relative increment of about $-1.3 \%$ in FF. This yields a $-26 \%$ increase in efficiency. PS films formed on textured c-Si substrates exhibit higher porosity and PL efficiency, negligible PL decay, better mechanical strength, adherence to the substrate, non-fractured surface morphology and lower stress compared to porous silicon formed on polished C-Si substrates at the same current density and demonstrate the viability of possible application of PS films in Si-solar cells. PS surface morphology on textured emitters in solar cells, as seen by SEM, shows that PS formation does not degrade the unprotected front metallic grid pattern. AFM measurements of PS ARC on textured emitters in solar cells reveal that the maximum pore size is $-500 \mathrm{~nm}$ long and $-50 \mathrm{~nm}$ wide whereas the minimum 


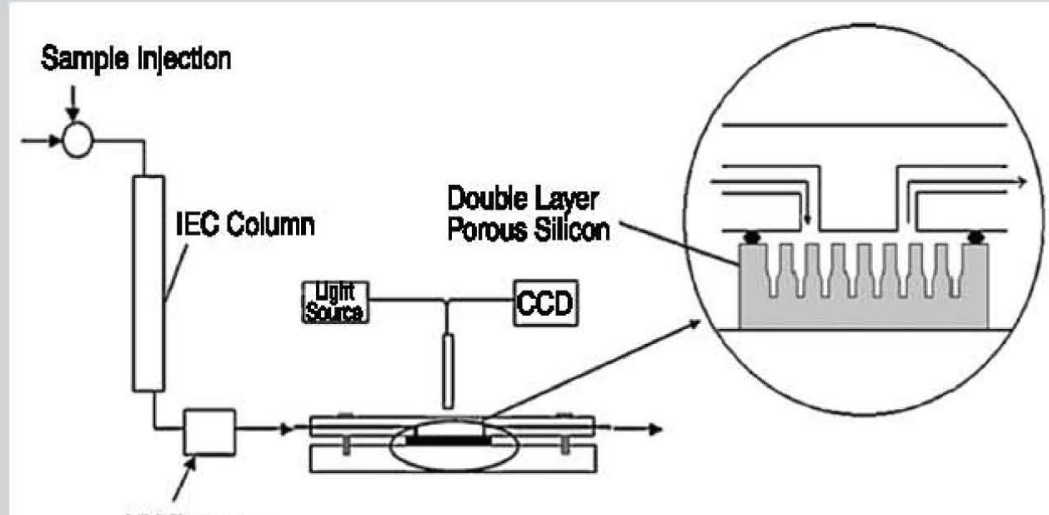

UN Detector

Flgure 9. The LC-UV-FTRIFS system, which Includes a chromatographlc column hyphenated with a UV detector and FIRIFS biosensor in series. A tungsten light source is focused on a porous silicon surface through optical fiber probe, and the interferometric reflectance spectra of porous sillcon are collected using a CCD spectrometer coupled to a bliturcated fiber optlc cable.?

pore size is $-150 \mathrm{~nm}$ long and $-30 \mathrm{~nm}$ wide. Fourier transform infrared and PL spectra are utilized to characterize the PS films of various thicknesses. Fourier transform infrared results show passivating capabilities of PS films and, therefore, allow fabricating solar cells without an additional passivation coating. The study of the optical properties by PL spectra show that the increase in the PL intensity may be attributed to the presence of $\mathrm{Si}-\mathrm{H}$ and $\mathrm{Si}-\mathrm{H}_{2}$ bonds with increase in PS film thickness.

Porous silicon biosensors based on optical interferometry and light emitting properties are discussed. For an optimized current density, the functionalization of the PS surface has been achieved by silanization method using APTS as a precursor. The presence of reactive amino groups on the PS surface along with glutaraldehyde as the linker aids in the covalent binding of the antibody (Human IgG) onto the PS surface leading to detection of different antigen concentrations with a good reproducibility.

\section{Reterences}

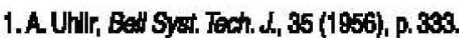

2. H. Oupang of al., Adk Fund. Mathr, 15 (2005) p. 1851.

3. B. Hamilton, Semicond. SA. Technol, 10 (1925), p. 1187.

4. VV. Doan and Mad Salor, Sckence, 256 (1992), p. 1791.

5. M.J. Sator, J.L. Heinrich, and J.M. Lauerhaas, Semtcond. Nanocrystals, ed. RY. Kamat and D. Malsel, (New Tork Elsevier, 1986), p. 100.

6.VS.Y. Lin et al. Scienco, 278 (1987), p. 840.

7.V. Parkthutik, Salfid Stat Electron, 43 (1999), p. 1121. 8.L. De Stetano ot al, Sensors, 7 (2CO7) p. 214. Q.S.M.Weles at al., Opt Express, 13 (2005), p. 1090 10. F.P. Mathew and E.C. Alocifa, Biosensors Biooloc- $\operatorname{trn}, 20(2005)$, p. 1656 .

11. F. Beseevills of el., Blibesens. Blostect, 21 (2005), p. 900 .

12. C. Pacholski ot al, J. Am. Chem. Soc, 127 (2005), p. 11638.

13. K. Watanabe, ot al., Sens. Actut B: Chem, 33 (1986), p. 194.

14. A. Foucaran of al, Thin Soffo Fitms, 297 (1997), p. 317.

15. C. Baratto et al, Sens Actrabors B: Chem, is (2000), p. 257.

16. L Boarino et al., Mater. Sci. Eng. B, 69 (2000), p. 210.

17. C. Baratto et al., Sens Achrabors B: Chem., 77 (2001), p.62

18. A.G. Culls, LT. Canhem and P.D. Cakeoth, J. AppL Phys., 82 (1997), p. 909.

19. S. Bastide ot al., Sol. Eng Males. Sol. Cetts, 57 (1999), 2.393.

20. R. R. Blyalow ot al, Sol. Eng. Matar. Sol. Ceth, 65 (2001), $\mathrm{p} .477$.

21. A. Krotkus of al., Sol. Eng. Mater. Sol. Colls, 45 (1997), p.267.

22. L. Stalmans et al. Sol. Eng. Mater. Sol. Celle, 59 (1999), p. 287.

29. Z. Swialsk ot al., Mater. Sai. Eng B, 101 (2009), p. 201.

24. L Canham, Propertias of Porous Silicon (London: INSPEG, 1997).

25. KH. Beckmann, Sutace Science, 3, (1965) p. 324. 28. R.J.Auther, J. Phys Chem. Sorids, 14 (1960), p.14 27. J. Dlan ot al, App. Surt SCl, 238 (1-4) (2004), p. 169.

28. S. Strehlke ot al., Mat Sai. Eng. B, 69-70, (2000), p. B1.

29. B.J. Thampen, Thin Filns for Cptical Systems (New Yoric Marcel Dedker Inc, 1995), p.285.

30. MA. Green, Solar Cento (Upper-Saddle River, NJ: Prentice-Hall Inc., 1982), p. 164.

31. J. Zhao and M.A. Green, IEEE Trans. Elect Dev, 39 (1991), p. 1825.

32. 2 Chen at al, IEEE Trans. Elact Dow, 40 (1999), p. 1161.

33. G. Zhang, J.Zhao, and M.A. Green, Sol. Eng. Mater: Sol Cells, 51 (1808), p. 393.

34. S.E. Loe, S.W. Chd, and J.Y, Thin Solld Flyos, 376 (2000), p. 208.

35. R.F. Bihalow et al., Proce 26) IEEE Photowol. Spec Cont, (Piscatancy, NJ: IEEE, 1987) p. 147.

36. J.H. Kwon, S.H. Lee, and B.K. Ju, L Appl. Phys., 101 (2007), 104515.

37. ZN. Adanian ot al., Sol. Eng. Wat Sol. Cells, 64 $(2000)$, p. 347.
39. S. Eglesh, Laser Focus Word, 45 (12) (2009), p. 39. 39. L Kore and G. Bosman, Sal. Eng. Mater. Sol Calls, $57(1999), p 31$.

40. D. Deresmes ot al., Thin Salld Fints, 255 (1995), p. 258.

41. M. Schnell, f. Lüdemann, and S. Schester, Proc. f6th Eur. Comm Photovol Sol Eng. Cond, ed James and James (Lendon: Earthecan Publcations Lid. 2000), p. 1492

42. R.J. Martin-Palma of al., Semicond Sci. Fechnol, 16 (2001), p.65.

43. L. Schlrone at al, Proc Sec. Wond Cont Fhatwol. Eng. Corw, (1999), p. 276.

44. Privanka Singh, "Fabrication, Cheracterization and Other Related Studies for Pertormance Improvenent of Crystalline Siticon Solar Celts" (Ph.D. Thesis, Nalional Physical Laboretory and Jemla Malla blamla, New Deilhi, India, 2008).

45. Prijanka Singh of al., Sol. Eng Mat Sol. Coffs, 9 (2007), p. 1510.

46. P. Singh et al, Adx Mator Fias, 31 (2018), p 249.

47. K.H. Jung, S. Shth, end D.L Kuong d. Electrocthen. Sac., 140 (1993), p. 3046.

48. S.N. Sham R.K. Sharma, and S.T. Laksthmikumar, Phystea E, 20 (2015), p. 264.

49. T.M. Cahn, Bbosensors (London: Chapmen \& Hal, 1999).

50. N.M. Ravindra of al., JOM, 59 (12), (2007) p. 37.

51. لل. Hickman et al, Science, 252 (1891), p. E8B.

52. H.M. Mocomell et al, bid, 257 (1992), p. 1906.

59. A. Brecht and G. Geugtz, Bicoens, Biosioctron, 10 (1995), p. 922 .

54. S.N. Sharma et al, Mater. Soi. and Eng. B, 127 $(2006)$, P. 255.

55. Q. Bhegavannarayana of al., Mator. Chem and Phys, 97 (2-3), (2000), 10. 442.

56. S.N. Sharma of al., Physica ELow-Dimens. Sys \& Nanostu, 38 (1), (2007), p. es.

57. A. Lenshofi ot al., LAm. Chem. Soc, 120 (1989), p. 12108.

58. J.M. Buriak of al., J Am Chem. Soc, 121 (1990), p. 11491.

59. S. N. Sharma et al., Appd. Surf. Scl., 182 (2001), p. 333.

60. S.N. Sharma, R. Bangjeo, and AK Barua, Cur. Apa Phs., 3 (2003), p. 289.

61. L Mongo ot al, Aral Bloenal. Chem, 385 (2906), p. 146.

62. L De Stetano at al. J. Opt A: Pure Appol Opt, 8 (2008), p. 5540 .

69. S. singh of al, L Maler Sol: Mator. Med, 20 (2000), p. 181.

64. M.P. Stowart and J.M. Buriak, Ack Mator, 12 (2000), p. 859.

65. A. tane et al, Thends in Biotech, 27 (2019), p. 230. 6\%. Sllleon Knotics, Inc, 10455 Pactilic Center Court, Sen Diego, CA 92121; mususiticontünatics.conv.

67. S. Sotau at al., Phys Stat. Sofid A : Apat Res, 204 (2007) p. 1434.

6. LM. Bonamo and LA. De Loulea, Blowens. Bhostectron., 20 (2007), p. 444.

69. H. Oryang of al., Ang! Chem, 79 (2007), p. 1502

70. A.M. Rossi of al., Biosens Biostocton, 23 (2007), p.741.

71. K.P.S. Denc, D.P. Geiner, and Mal, Salor, $\alpha$ Am. Chem. Soc, 121 (1999), p. 7925.

72. Y. Sthang of al., Biosens. Biodection, 25 (2010), p. 1056.

Prtynle Shah, resercher, and Nuggehelll Revindie profossor and chalr, are wth the Physins Department, Now Jareery Inettuts of Technolegs, 161 When Street, Newark, WW 07102; 8halleeh N. Sharma, aclentlat, Is with the National Phylcal Lreoratory Eloctronle Matertas Dhlsion, Semt conductor building Dr. KS. Krishnan Merg St, New Delhl 110012, Indala $D$. Rnindra can be reached it (978) 586-5742, fax (973) 596-5794; 6-mell nmroutdraegrnalleom. 